\title{
Mini Cholecystectomy: A Comparison with Laparoscopic Cholecystectomy
}

\author{
A AHMAD H M KHAN S GULSHAN T $A$ SHAH \\ Department of Surgery, King Edward Medical College/Mayo Hospital, Lahore \\ Correspondence: Dr Ashfaq Ahmad, Assistant Professor SurgeryE mail: ashfaq156@hotmail.com.
}

Laparoscopic cholecystectomy is the gold standard procedure for symptomatic gallstones but at a higher price. Recently a few studies comparing mini cholecystectomy to laparoscopic cholecystectomy have shown that mini cholecystectomy has comparable results to laparoscopic cholecystectomy at an affordable price. We compared these two techniques over a period of two years.224 patients were studied, 122 had laparoscopic and 102 had mini laparotomy cholecystectomies. Results showed that operation time and theatre cost were low in mini laparotomy cholecystectomies but these patients required more post operative analgesics. There was no significant difference in total hospital stay and resumption to routine activities. Total cost to hospital and patient was also similar for these two techniques. There were two common bile duct injuries in laparoscopic group and none in mini cholecystectomies and there was no mortality in either group. We conclude that results of mini laparotomy cholecystectomy are very much similar to laparoscopic cholecystectomy and it can be used as an alternative to laparoscopic technique.

Key words: minicholecystectomy, laparoscopic cholecystectomy

Cholecystectomy is one of the most common procedures performed in general surgical practise. It is most effective and widely practised treatment for symptomatic gallstones. Four essential methods used now a days for removal of gall bladder i.e. standard open cholecystectomy, mini laparotomy cholecystectomy, standard laparoscopic cholecystectomy and mini laparoscopic cholecystectomy. Since its introduction in 1990, laparoscopic cholecystectomy has replaced open cholecystectomy as routine standard procedure except for difficult cases. This approach has now been challenged by the introduction of mini laparotomy cholecystectomy and mini laparoscopic cholecystectomy.

Aim of our study is to compare laparoscopic and mini laparotomy cholecystectomy in terms of procedure time, post operative recovery, total stay in hospital and cost.

\section{Materials and methods:}

This is a retrospective study of our experience of cholecystectomies at west surgical unit, mayo hospital Lahore over a period of two years from September 2003 to august 2005.

All acute or elective patients who had laparoscopic cholecystectomy or mini laparotomy cholecystectomy were studied. Cholecystectomies performed only by the consultants were included in the study. Patients who had common bile duct exploration were excluded. All laparoscopic or mini laparotomy cholecystectomies that were converted to open, cholecystectomy were also excluded. All patients were well matched for base line characteristics like, age, sex, body mass index etc. Laparoscopic cholecystectomies were performed by a standard 3 or 4 port technique. Maximal length of the incision for mini laparotomy cholecystectomy was $5 \mathrm{~cm}$. Rectus abdominis muscle was retracted but was also divided when required. A single vicryl suture was used for the total operation i.e. ligation of cystic duct, cystic artery and wound closure, in majority of cases. Bupivacain was injected in the wound and abdomen was closed without drain. Operation time was counted from the induction of anaesthesia to extubation. Total analgesic requirement was recorded on patients' charts. Other parameters noted were total hospital stay, average cost of the procedure and complications.

Results

A total of 224 patients were included in the study. 122 patients underwent laparoscopic cholecystectomy (54\%) and $102(46 \%)$ had mini laparotomy cholecystectomy.

Table 1: Type of procedure

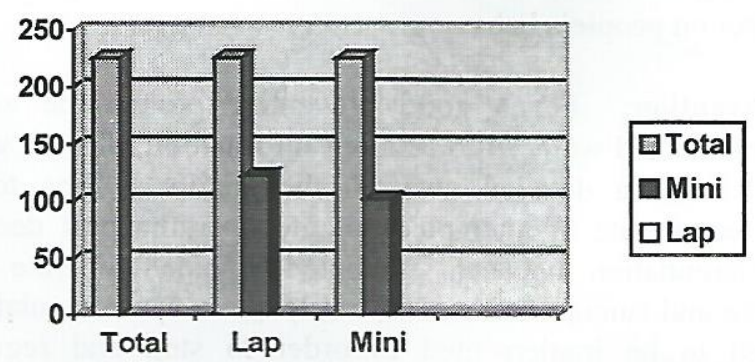

Mean duration of operation for laparoscopic cholecystectomy was 78 minutes with a range of 55 to 129 minutes, while mean time for mini laparotomy cholecystectomy was 62 minutes with range of 40 to 95 minutes.

Laparoscopic patients group had a mean of $15 \mathrm{mg}$ of nalbuphin and $100 \mathrm{mg}$ of diclophenac, while mini cholecystectomy patients had $25 \mathrm{mg}$ of nalbuphin and 150 $\mathrm{mg}$ of diclophenac. There was no difference in time to resumption to liquids or solid food between the two 
groups. Mean hospital stay was 2.5 days for laparoscopic group and 3 days for mini laparotomy group. (Table 2)

Table 2: operative and post operative data

\begin{tabular}{lll}
\hline & $\begin{array}{l}\text { Theatre } \\
\text { time } \\
\text { (minutes) }\end{array}$ & $\begin{array}{l}\text { Hospital stay } \\
\text { (days) }\end{array}$ \\
\hline $\begin{array}{l}\text { Laparoscopic } \\
\text { cholecystectomy }\end{array}$ & $55-129(78)$ & $1-9(2.5)$ \\
$\begin{array}{l}\text { Range (mean) } \\
\text { Mini cholecystectomy }\end{array}$ & $40-95(62)$ & $1-4(3)$ \\
$\begin{array}{l}\text { Range (mean) } \\
\text { P value }\end{array}$ & 0.79 & 0.68 \\
\hline
\end{tabular}

Mini cholecystectomy was more economical to patient and hospital as compared to laparoscopic procedure.

Complications are shown in table 3. Two patients in laparoscopic group had iatrogenic injury to common bile duct, which was identified immediately and was managed by converting to open procedure and $\mathrm{T}$ tube placement. One patient in mini cholecystectomy group had haemorrhage in wound secondary to wound infection on 11 th post operative day.

Table 3: complications

\begin{tabular}{lll}
\hline Complications & Lap Chole & Mini Chole \\
\hline Bile duct injury & 2 & 0 \\
Wound infection & 5 & 6 \\
Secondary haemorrhage & 0 & 1 \\
Injury to adjacent viscera & 0 & 0 \\
Others like, M I, DVT, PE & 0 & 0 \\
\hline
\end{tabular}

\section{Discussion}

Laparoscopic and mini laparotomy cholecystectomies are relatively new techniques. Mini laparotomy cholecystectomy was first described in $1982{ }^{1}$ but it was overlooked due to enthusiasm about laparoscopic surgery. For past few years there were studies comparing these two techniques $^{2,3,4}$. We compared these techniques in terms of operation time, post operative recovery, analgesic requirement, duration of stay in hospital, cost of procedure and complications.

Operation time was significantly longer in laparoscopic procedure (table 2). Similar results are shown in all other studies ${ }^{5,6,7}$, and it also contributed to the higher operating room cost for laparoscopic cholecystectomy ${ }^{8}$. Post operative analgesic requirement was higher in mini cholecystectomy patients initially, probably due to retraction but later we started using bupivacaine injection in the wound which provided good pain relief in the immediate post operative period. Both techniques had no significant difference in total duration of stay in hospital and complications. Mini cholecystectomy is more economical than laparoscopic cholecystectomy and there are few well designed studies showing clear benefit of mini laparotomy cholecystectomy over laparoscopic procedure in terms of $\operatorname{cost}^{7,8}$. Overall incidence of bile duct injury is higher in laparoscopic cholecystectomy than for open technique In our study there were two injuries to common bile duct in laparoscopic group and none in mini cholecystectomies. Mini laparotomy cholecystectomy is beneficial in certain situations where pneumoperitoneum may be hazardous or difficult like, old patients with cardiopulmonary disease ${ }^{9,10}$, previously scarred abdomen and pregnant women. Although laparoscopic cholecystectomy is increasingly being performed for acute cholecystitis successfully but it has a high conversion rate leading to increased theatre time and cost ${ }^{11}$.

We conclude that mini laparotomy cholecystectomy and laparoscopic cholecystectomy have comparable results.

\section{References:}

1. Dubois F, Barthelot B. Cholecystectomie par minilaparotomie. Nouv Presse Med 1982;11:1139-41.

2. Barkun JS, Barkun AN, Sampalis JS, et al. Randomised controlled trial of laparoscopic versus mini cholecystectomy. The McGill Gallstone Treatment Group. Lancet 1992;7:340:1116-9.

3. Barkun JS, Caro JJ, Barkun AN, et al. Cost-effectiveness of laparoscopic and mini-cholecystectomy in a prospective randomized trial. Surg Endosc 1995;9:1221-4.

4. Syrakos T; Antonitsis P; Zacharakis E; Takis A; Manousari A; Bakogiannis K; Efthimiopoulos G; Achoulias I; Trikoupi A; Kiskinis D. Small-incision (mini-laparotomy) versus laparoscopic cholecystectomy: a retrospective study in a university hospital. Langenbecks Arch Surg 2004 Jun;389(3):172-7

5. Ros A, Gustafsson L, Krook H, Nordgren CE, Thorell A, Wallin G, Nilsson E. Laparoscopic cholecystectomy versus mini-laparotomy cholecystectomy - A prospective, randomized, single-blind study. Annals of surgery 234 (6): 741-749 Dec 2001.

6. Sharma $\mathrm{AK}$, Rangan $\mathrm{HK}$, Choubey RP. Mini-lap cholecystectomy: A viable alternative to laparoscopic cholecystectomy for the Third World? Aust N Z J Surg 1998;68:774-7.

7. Tate JJ, Lau WY, Leung K L, Li AK. Laparoscopic versus mini-incision cholecystectomy.Lancet. 1993 May 8; 341(8854):1214-5.

8. Neil W Calvert, Gill P Troy, Alan G Johnson. Laparoscopic cholecystectomy: A good buy? A cost comparison with small incision (mini) cholecystectomy. Eur J Surgery 2000; 166: 782 - 786 .

9. Changes in splanchnic blood flow and cardiovascular effects following peritoneal insufflation of carbon dioxide. Surg Endosc 1993; 7:420-3.

10. Koksoy C, Kuzu MA, Kurt I, et al. Haemodynamic effects of pneumoperitoneum during laparoscopic cholecystectomy: a prospective comparative study using bioimpedance cardiography. Br J Surg 1995;82:972-4

11. Johansson M, Thune A, Nelvin L, Stiernstam M, Westman B, Lundell L. Randomized Clinical Trial of Open Versus Laparoscopic Cholecystectomy in the Treatment of Acute Cholecystitis. British Journal of Surgery. 005; 92 (1) : 44-49 